\title{
DESIGN OF MULTI-WEAR ACCESSORIES CLOTHING AS A CONTEMPORARY FASHION INSPIRED BY THE TRADITIONAL CLOTHING OF MENOUFIA
}

Rehab Adel Shaker EL-FISHAWY *

Apparel and Textile Department, Faculty of Home Economics, Menoufia University, Egypt

\begin{abstract}
The folklore in Menoufia Governorate represents one of the most important folk legacies that confirm our Egyptian identity, and this heritage represents its important and influential values in our national heritage as it is characterized by simplicity, innate nature and dependence on the surrounding environment, and preserving this popular heritage and reformulating it in a way that is in line with contemporary reality is the problem of this Research in the analysis of the most important features that characterized the popular costumes in Menoufia governorate from its distinctive elements and features, the possibility of designing multi-wear clothing supplements as a contemporary fashion inspired by the heritage clothes of the Monufia Governorate, and determining the opinions of specialists in the designs implemented and the extent to which they achieve the innovative aspect of the heritage clothing The extent to which the functional aspect was achieved and in order to achieve the research objectives, the most important features that characterized the traditional clothing in the Menoufia Governorate were analysed from distinct elements and features. Five sets of multiple-wearing clothing supplements (accessories - shawls) were designed and implemented, inspired by the aesthetics of traditional clothing in the Menoufia governorate, the village of RamlaAnjab. And presented to a number of judges in the field of specialization to gauge the extent of the designs' success Preserving heritage through the questionnaire card includes three axes: The extent of inspiration from traditional clothing - the extent to which the innovative aspect is achieved - the extent to which the functional aspect is achieved, as there were statistical differences between the evaluation axes and the various designs. The designs were arranged as follows: The fourth model surpassed the rest of the models at the level of axes. The evaluation received $97 \%$, followed by the second model and the third model $91 \%$, then followed by the fifth model, where he got $95 \%$ and the first model, as it was the lowest designs with a quality factor of $82 \%$. The researcher recommends paying attention to folk media as a source of inspiration for women's fashion and deepening the idea of belonging to women The ad. Searching for local fashions that emphasize our Egyptianness among the fashions and fashions of the contemporary world.

\section{Keywords}

Design, Multi-Wear Accessories, Clothing, Fashion, Traditional.
\end{abstract}

\section{Introduction}

Throughout the ages, folklore has been considered a source of popular culture, as it is an ammunition and a national revolution. Those in charge now must reveal the roots of our heritage, our authenticity, and try to employ it with a new vision in line with the prevailing fashion and stems from our national identity. This comes through the use of the scientific method and theory through which it is possible to understand the aesthetic trends characterized by originality and renewal, and to realize the aesthetic values, in order to reveal the areas of beauty in the ancient heritage by meditation based on focus. Popular costumes are the best representations of our national identity, as they convey to us symbolic meanings hidden and the motifs and embroideries of the human life and his environment, as it is considered a space vibrant, bloody and developmental, and it is the intellectual legacy accumulated thanks to the

*Corresponding author: econo_home@menofia.edu.eg 
efforts of successive generations and given that we live now in an era of more intense moons and the advancement of modern media technology Industrial, satellite channels, and the information network, all of which work to melt cultural subjectivity and remove popular legacies, to be replaced by Western cultural values, and with our occurrence and absence, and the Arab society in the families of the incoming foreign currents and ideologies that have dominated the minds for a long time and obliterated the creativity resulting from our work and culture. Of transport and simulation do not agree with our Arab character and character, which requires confirmation of the Egyptian folklore and its revival due to the high prices of clothes, and the interest of women in change and what increases their purchase of clothing items, so the interest came in ways to rationalize the consumption of clothes. This is the idea of how to multiply the use of clothes as a way to save a budget for buying new clothes by making some changes to the piece of clothing. Hence, the researcher sees the necessity of linking the modern fashion trends of 2018 with the folklore of the subject of study, and by that we will link originality with modernity by designing multiple-wear clothing supplements as a contemporary fashion inspired by the traditional clothes of the Menoufia Governorate of RamlehAnjab, the heritage is the value of our Egyptian state, and where the popular heritage represents In Menoufia Governorate, one of the most important popular legacies that affirm and influence our national heritage, as it is characterized by simplicity and innate nature and reliance on the surrounding environment that can be reformulated in a way that is compatible with the best way to confirm our cultural and Arab specificity.

\section{Research Problem}

- The problem of this research is that we must develop in the traditional culture, especially in the inherited customs represented in the heritage that has disappeared in some countries of the world

- The loss of the design idea of the folklore of Menoufia Governorate in the design of Egyptian fashion.

- The tyranny and domination of the culture of the machine age and the families of the incoming foreign currents and ideological sects and their destruction of the creative spirit stemming from the popular culture.

\section{Defining the Research Problem in the Following Questions}

1. Is it possible to analyze the most important features and characteristics that distinguished the traditional costumes in Menoufia Governorate?

2. To what extent is it possible to design multi-wear accessories as a contemporary fashion 
inspired by the traditional clothing of Menoufia Governorate?

3. What are the opinions of the specialists in the designs implemented and the extent to which they achieve the inspiration from the traditional clothes?

4. What are the opinions of the specialists in the designs implemented and the extent to which the innovation side has been achieved?

5. What are the opinions of specialists in the designs implemented and the extent to which the functional aspect has been achieved?

\section{Menoufia Governorate}

Menoufia Governorate, an Egyptian governorate, is located north of the Egyptian capital, Cairo, in the south of the Nile Delta, and its capital is the city of Shebin al-Kom, and its largest city is the city of Sadat, which was cut from the Buhaira governorate in 1991 (since 26 years). Its population is calculated by and is limited to about half of the governorate's area between ${ }^{2}$. The official census is $3,270,404$ in 2006 , and its area is $2,543.03 \mathrm{~km}$. The Nile River branches, Damietta and Rashid, while the other half extends as a desert dahir west of the Rashid branch to include the Sadat Center, the largest of the governorate. In general, Monofeya consists of 9 administrative centers that include 10 cities. : Shebin al-Kom, Menouf, Sadat City, Sars alLayyan, Ashmoun, Bajur, Quesna, Birkat al-Sabaa, Tala, and al-Shuhada) The main economic activity of the residents of the governorate is agriculture, because the ancient lands of Menoufia between the two branches of the Nile are characterized by fertile soil and the abundance of irrigation water permanently from the Nile River, as well as agriculture. Sadat is through land reclamation.The governorate has all kinds of cash crops, vegetables and fruits. Industrial activity also strongly contributes to the agricultural activity, especially after the annexation of Sadat city to the governorate, which is one of the largest industrial cities in Egypt. In addition, there are other industrial zones in the city of Quesna, in addition to light industries in Shebin al-Kom. The governorate of Menoufia ranked eleventh in 2006 in the ranking of the Egyptian governorates in the Nile Valley and the Delta in terms of quality of life and the sophistication of services, as for roads and transportation. The governorate is crossed by two of the most important roads in Egypt, the first of which is the Cairo-Alexandria agricultural road, and the second is the Cairo-Alexandria desert road, while most of the remaining roads in Menoufia suffer from their poor condition and neglect despite the large number of transport links that connect most parts of the governorate to each other.

\section{Ashmoun Center}

Geographically: Eshmun Center is located in the far south of the governorate, between the Damietta and Rashid branches. The Eshmoun district occupies $12.06 \%$ of the total area of the 
governorate

\section{Administrative Division of Ashmoun Center}

The center includes twelve village local units, which are: Talia, Darwah, Qors, Saqiyat Abu Shaara, Centris, Shatanouf, Sabk al-Ahad, Shanshor, Samadun, Ramlet al-Anjab, Shamma, and Tahawi. They are also followed by 54 sub-villages and $190 \mathrm{Kufr}$ and Naga, the villages of Ashmoun, Al-Nanaiyah, Al-Kuwadi, Al-Qanaterin, Al-Faraounia, Al-Ghannamiya, Al-Khor, Al-Halawasi, Al-Baraniyya, Al-Anjab, Abu Awali, Abu Raqba, Samadun, Sabak, Al-Ahad, Saqiyat al-Muqdi, Saqiyat Abu Sha'ara, Ramlet alAnjabDelhomoDarwahGiresBuhaShatanoufBarrashimTahaway Talia SarawahShushaiShenwayShanshorShammaShashaaShatanoufSohawag Centers SmlayKafr El-FarouniaKafr El-GhorayebKafr El-TarainaKafr Al-SayedKafr Al-Hama • Kafr Abu Mahmoud · Kafr Abu Raqba - QusManialJuwaida · Jereis facility · Locality Sobak · Hungary - Lebisha · KomAyyad · Kafr Mansour - KafrAoun · KafrQureus · SarawatManialAounArous 20 - ManialDawibRamlaAnjab: Ramlet al-Anjab is one of the villages Eshmoun Center in Menoufia Governorate, Arab Republic of Egypt. Population: The population of Ramleh AlAnbab reached 8,493, according to the official census of 2006

\section{Results}

The first question: "Is it possible to analyze the most important features that distinguished the traditional costumes in Menoufia governorate from its distinctive elements and features?" To answer this question, the researcher conducted an analytical study of the traditional clothes for the Governorate of Menoufia (the village of RamlehInjeb) and analyzed its elements, features and characteristics.

\section{Recommendations}

1- The research recommends the necessity of conducting studies and research on the creative industries that have become basic industries that contribute to the development of the economy in general.

2- Setting rules and legislations to protect the rights of creative production and supporting creative industries are among the priorities of cultural policies.

3- That the designer has a great understanding of sustainability principles.

4- Development of cultural, environmental and economic awareness among the segments of society. 


\section{References}

1. Saad Al-Khadem: The History of Popular Costumes in Egypt, General Assembly of the Book, Cairo, 2007

2.Dr / Rashakil, and Dayan Medin: Designing contemporary clothes inspired by ancient Egyptian clothes and the decoration of the Nubian architecture in light of ethical fashion, International Design Magazine, April 2016

3. Ibtisam Muhammed Abd al-Wahhab: The Factors Affecting the Techniques of Egyptian Folklore from Their First Sources to Establish Identity in Interior Design - International Design Journal - Volume Four, Issue One, 2014

4. Majida Ibrahim Al-Aswad, An Applied Technical Study of Popular Costumes in Menoufia Governorate, Faculty of Home Economics, Menoufia University, 1994.

5. Amani Ahmed Ibrahim Jouda, the Egyptian popular fashion and its inspiration of designs that raise the level of quality in order to allow for competition. Master, Faculty of Home Economics, Menoufia University, 2000

6. Nirmen Abd al-Rahman Abd al-Basit, making use of the folklore in the governorates of Damietta and Marsa Matrouh to manufacture clothes. Child Brides for the Development of his Artistic Culture, Ph.D., Faculty of Home Economics, Helwan University, 2001

7. Mona Ahmed Youssef Qasim, a plastic vision of popular decorations and their symbolic connotations, and how to make use of them in the field of clothing. And its supplements, MA, Faculty of Home Economics, Helwan University, 2006

8. Osama Mahmoud Al-Sayeda, who established some traditional Egyptian costumes and used them to design and implement clothes. Al-Shabab, MA, Home Economics, Menoufia University, 2007

9. A group of scholars and researchers: The Facilitated Arab Encyclopedia, Dar Al Jeel, and the Egyptian Association for the Diffusion of Knowledge and International Culture, Beirut Cairo. , 2009AD

10. Hassan Alfar: Printed Fabric Designs and Their Relationship to Fashion, Sixth Conference of Home Economics, Faculty of Home Economics, Helwan University, Cairo. $2000 \mathrm{~m}$

11. Nadia Mahmoud Dakhil, “A Study of the Impact of Grooming Supplements on Fashion in the Islamic Era" - a message from the Master of the College of Home Economics. Helwan University - 1982

12. Ibn Munzur Lisan Al-Arab "Article“ Worthdar Sader"- for sellers and publishers - Beirut - 1994

13. The tasks of Hammoud Ibrahim: Turkism in popular art and its impact on the Nubian input 
at the Sixteenth International Conference of Philadelphia - Jordan - 2013

14. Habha Hamedis - An Empirical Study of Tariq Fashion in Islamic Times - Home Economics Journal - The Tenth Arab Conference 7 (August 2006-8)

15. Ali Zalat, Fashionable Fashion, Local and International, Home Economics Research Bulletin, Menoufia University - July and October - 1995

16. Hanan Ahmad Tantawi Ahmad ": Investing the Beauty of Selections of Marine Organisms in New Publications -" for the one-piece fashion for women, the printing house - Faculty of Art Education - Unpublished Doctorate Message - Helwan University 2005

17. Khalidi Essam Shaheen: Creating a database with the aim of producing fashionable menus designs, designing textiles, typography, a master's letter, a master's publication - Helwan University - College of Applied Arts - 2005

18. http://en.wikipedia.org/wiki/Fashion_accessor

19. http://almaany.com

20. https: ar.wikipedia.org.com

21. https://www.behance.net/gallery/30149557/Trend-Book-SpringSummer-2018

Received: February 15, 2018

Accepted: April 20, 2018 